\title{
Oficina temática: uma proposta metodológica para o ensino do modelo atômico de Bohr
}

\section{Thematic workshop: a methodological proposal for the teaching of the Bohr atomic model}

\author{
Giovanna Stefanello Silva ${ }^{1}$. Mara Elisa Fortes Braibante ${ }^{2}$. Hugo Tubal Schmitz \\ Braibante $^{3}$. Maurícius Selvero Pazinato ${ }^{4}$. Marcele Cantarelli Trevisan ${ }^{5}$
}

\begin{abstract}
Resumo: A pesquisa apresentada neste artigo é de caráter qualitativo e investigou a aprendizagem dos conceitos relacionados ao modelo atômico de Bohr pelos alunos de uma turma da primeira série do Ensino Médio, durante o desenvolvimento de uma oficina temática. Nessa oficina, foi realizada uma atividade experimental que abordou a emissão de luz proveniente dos saltos eletrônicos que ocorrem em compostos contidos nas lightsticks, pulseiras distribuídas em festas, e teve por objetivo relacionar os fundamentos propostos por Bohr com aspectos do cotidiano dos estudantes. A pesquisa foi aplicada em uma escola de Ensino Médio da cidade de Santa Maria, Rio Grande do Sul, e os resultados obtidos nos permitem afirmar que a oficina temática desenvolvida contribuiu para a aprendizagem dos conceitos relacionados ao modelo atômico de Bohr.
\end{abstract}

Palavras-chave: Ensino Médio. Oficina temática. Modelo atômico de Bohr. Aprendizagem.

\begin{abstract}
The research introduced in this paper is a qualitative review and it investigated the apprenticeship of the concepts related to the Bohr atomic model by the students from the first grade in high school during a thematic workshop. In this workshop, there was an experimental activity in which light emission from the electronic jumps which occur in compounds present in lightsticks, bracelets handed out in parties, was presented. The purpose was to associate the assumptions proposed by Bohr to aspects of the daily life of the students. The research was carried out in a high school in the city of Santa Maria, Rio Grande do Sul, Brazil and the results obtained allow us to assert that the developed thematic workshop contributed to the apprenticeship of the concepts related to the Bohr atomic theory.
\end{abstract}

Keywords: High school. Thematic workshop. Bohr atomic model. Apprenticeship.

\footnotetext{
${ }^{1}$ Programa de Pós-Graduação em Educação em Ciências, Universidade Federal de Santa Maria (UFSM), Avenida Roraima, Departamento de Química - Prédio 18, Sala 2119ª Camobi - km 9, Campus Universitário,CEP: 97105-900. Santa Maria, RS, Brasil. E-mail: giovannastefanello@gmail.com

${ }^{2}$ Departamento de Química, Universidade Federal de Santa Maria (UFSM), Santa Maria, RS, Brasil.

${ }^{3}$ Núcleo Ciência Viva, Universidade Federal de Santa Maria (UFSM), Santa Maria, RS, Brasil.

${ }^{4}$ Departamento de Metodologia do Ensino, Centro de Educação, Universidade Federal de Santa Maria (UFSM), Santa Maria, RS, Brasil.

${ }^{5}$ Programa de Pós-Graduação em Educação em Ciências, Universidade Federal de Santa Maria (UFSM), Santa Maria, RS, Brasil.
} 


\section{Introdução}

As aulas de Química ainda são desenvolvidas, em muitas escolas, por meio de atividades em que a parte conceitual é abordada por intermédio da repetição, fragmentação e esvaziamento do caráter social (MALDANER; SANTOS, 2010). O ensino de Química, quando baseado neste modelo, torna-se desinteressante para a maioria dos alunos (ROSENAU; FIALHO, 2008). Segundo Santos e Schnetzler (2003), o professor deve ter, por objetivo, a contextualização do conteúdo, permitindo o desenvolvimento de habilidades essenciais do cidadão. Ao contextualizar, o professor explicita o papel social da Química, suas aplicações e implicações, além de demonstrar como o cidadão pode aplicar o conhecimento em sua vida diária. Portanto, contextualizar é aproximar os conceitos escolares dos fatos presentes no dia a dia dos alunos (SILVA, 2003).

Para auxiliar na contextualização dos conteúdos científicos e no processo de ensino e aprendizagem, nosso grupo de pesquisa Laboratório de Ensino de Química (LAEQUI), da Universidade Federal de Santa Maria (UFSM) ${ }^{6}$, vem utilizando temáticas. A abordagem dos conteúdos de Química associados a uma temática não se restringe apenas a fornecer informações sobre processos produtivos, tecnológicos ou usos que a sociedade vem fazendo de materiais, mas utiliza a abordagem de dados, informações e conceitos, para que os alunos possam conhecer a realidade, avaliar situações, soluções, e propor formas de intervenção na sociedade (MARCONDES et al., 2007). Atualmente, vários temas têm suscitado pesquisas no ensino de Química, neste trabalho utilizamos a temática "A Química presente em sua festa" como nosso foco de estudo. Neste contexto, abordamos alguns conceitos químicos relacionados com essa temática na tentativa de aproximar a Química dos espaços sociais frequentados pelos estudantes.

Além da pouca contextualização, outro obstáculo no ensino de Química é a abstração dos conteúdos. Conforme Trindade (2010), para se compreender a Química, precisamos desenvolver a habilidade de transitar entre dois níveis de realidade: o macroscópico e o microscópico. A realização de atividades experimentais pode ser utilizada para superar essa dificuldade e auxiliar na visualização dos conteúdos abstratos da Química. Desde o século XVIII, a experimentação é reconhecida como uma ferramenta facilitadora do processo de ensino e aprendizagem em Ciências, já que auxilia na articulação entre fenômenos e teorias (SILVA; MACHADO; TUNES, 2010).

O entendimento da estrutura da matéria e da evolução dos modelos atômicos não é uma tarefa trivial para os alunos do Ensino Médio, devido ao alto grau de abstração desses conteúdos e a dificuldade que os mesmos têm de construir a ideia da evolução desses modelos. Na maioria das escolas o conteúdo de modelos atômicos é abordado somente de maneira teórica, sem a realização de atividades experimentais. O professor mostra sua evolução, fazendo apenas citações acerca do primeiro cientista que mencionou a ideia de átomo, até os modelos mais avançados, desconectado do contexto histórico-social. Para a aprendizagem ter significado, os alunos necessitam compreender que a Química não é uma Ciência pronta e acabada, é fruto de muitas tentativas, erros e acertos de cientistas que dedicaram seu tempo a tentar

${ }^{6}$ Disponível em <http://w3.ufsm.br/laequi/>. Acesso em: 08 maio 2014. 
entender e explicar o mundo em que viviam (FARIAS, 2007). A construção do modelo atômico, que hoje é aceito pela comunidade científica, vem sendo reformulada desde os séculos IV e III a.C., sendo que a ideia inicial de átomo foi desenvolvida pelos gregos (MAAR, 2008).

$\mathrm{Na}$ tentativa de auxiliar os estudantes na construção, visualização e aplicação dos conhecimentos envolvendo a teoria atômica, mais especificamente o modelo atômico de Bohr, planejamos e desenvolvemos uma oficina temática intitulada "A Química presente em sua festa". Nesta perspectiva, este artigo tem por objetivo relatar essa oficina temática que foi desenvolvida em uma turma da $1^{a}$ série do Ensino Médio da rede pública e apresentar os resultados obtidos nessa proposta metodológica.

\section{As oficinas temáticas como uma proposta metodológica para o ensino de Química}

As oficinas temáticas procuram tratar os conhecimentos de forma inter-relacionada e contextualizada, envolvendo os estudantes em um processo ativo na construção de seu próprio conhecimento (MARCONDES, 2008). Neste sentido, as principais características das oficinas temáticas podem ser resumidas:

- Utilização da vivência dos alunos e dos fatos do dia a dia para organizar o conhecimento e promover aprendizagens;

- Abordagem dos conteúdos de Química a partir de temas relevantes que permitam a contextualização do conhecimento;

- Estabelecimento de ligações entre a Química e outros campos do conhecimento necessários para se lidar com o tema em estudo;

- Participação ativa do estudante na elaboração do seu conhecimento (MARCONDES, 2008, p. 68-69).

As oficinas temáticas estão baseadas na contextualização e na experimentação conforme apresentado no Esquema 1.

Esquema 1. Fundamentos das oficinas temáticas.

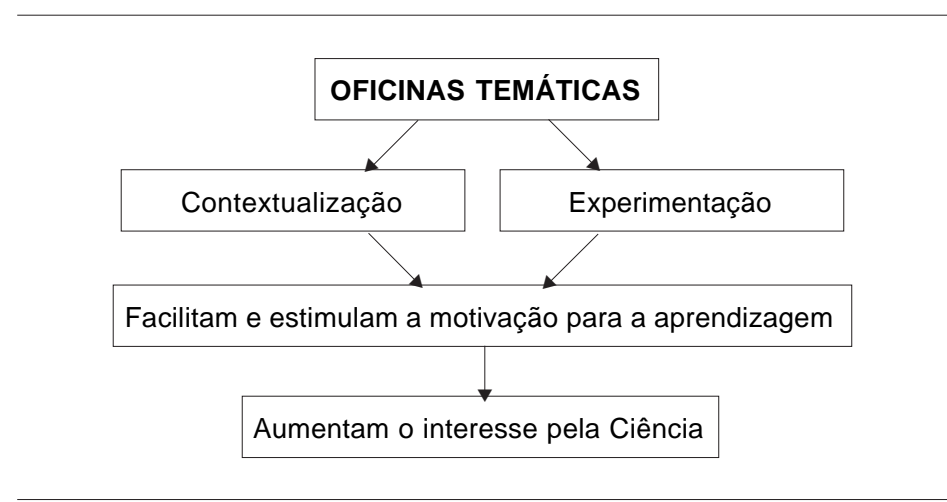

Fonte: Marcondes (2008). 
As oficinas temáticas são estruturadas com base nos momentos pedagógicos propostos por Delizoicov e Angotti (1991): problematização inicial, organização do conhecimento e aplicação do conhecimento.

No primeiro momento pedagógico, problematização inicial, são apresentadas, aos alunos, situações reais, cujo objetivo é fazer com que sintam a necessidade da aquisição de novos conhecimentos para compreendê-las. Na organização do conhecimento, segundo momento pedagógico, “[...] os conhecimentos selecionados como necessários para a compreensão dos temas e da problematização inicial são sistematicamente estudados nesse momento, sob a orientação do professor" (DELIZOICOV; ANGOTTI; PERNAMBUCO, 2009 , p. 201). O terceiro momento pedagógico, aplicação do conhecimento, destina-se a abordar sistematicamente o conhecimento que vem sendo adquirido pelo aluno, para que o mesmo possa reinterpretar o problema proposto e estabelecer relações entre os conhecimentos adquiridos com outras situações problemáticas.

\section{O modelo atômico de Bohr e sua relação com o cotidiano}

O modelo atômico proposto por Bohr baseou-se no modelo planetário de Rutherford, acrescentando elementos desconhecidos da mecânica clássica que permitem explicar uma série de teorias e fenômenos, até então não esclarecidos pelos modelos anteriores (FIGUEIREDO, 2008). A teoria atômica de Bohr foi publicada em 1913, baseada em quatro postulados, e sua principal contribuição foi em relação ao movimento dos elétrons nos átomos. Os elétrons dos átomos, ao absorverem energia suficiente, são excitados para órbitas mais externas, ao retornarem para o estado fundamental liberam essa energia na forma de luz, com comprimento de onda $(\lambda)$ que compreende as faixas de energia do espectro eletromagnético, dentre elas a faixa do visível (ABDALLA, 2006). Uma das consequências das transições eletrônicas descritas pelo modelo de Bohr é a possibilidade de visualização das diferentes cores observadas, por exemplo, nos fogos de artifício. Já as transições eletrônicas envolvendo moléculas, que ocorrem entre os orbitais moleculares, resultam nas diferentes cores observadas nas frutas, nos corantes, nas lightsticks, entre outros.

As lightsticks, pulseiras distribuídas em festas, eventos e comemorações, surgiram há aproximadamente vinte anos e são erroneamente conhecidas como "pulseiras de neon", devido a sua semelhança com letreiros luminosos que possuem o gás neônio como um de seus constituintes. Essas pulseiras brilham no escuro e seu funcionamento não está relacionado com o gás neônio, mas diretamente ligado a reações químicas (CRANOR, 2011). Neste trabalho, a fim de evitar a utilização dos termos lightsticks e "pulseiras de neon", no qual o primeiro é considerado um estrangeirismo e o segundo traz a ideia equivocada em relação à composição química da pulseira, optamos por denominá-las pulseiras luminosas.

O mecanismo de emissão de luz das pulseiras luminosas ocorre por meio do fenômeno chamado luminescência, que engloba a fluorescência, fosforescência, bioluminescência e a quimiluminescência. Na fluorescência, ocorre a emissão de um fóton de luz quando o elétron retorna ao estado fundamental; na fosforescência, o elétron excitado decai para um nível intermediário de energia, a partir do qual ocorre a emissão de radiação ao retornar ao estado fundamental (NERY; FERNANDEZ, 2004). 
A Figura 1 apresenta a diferença entre os processos de fluorescência e fosforescência.

Figura 1. Processos de fluorescência e fosforescência.

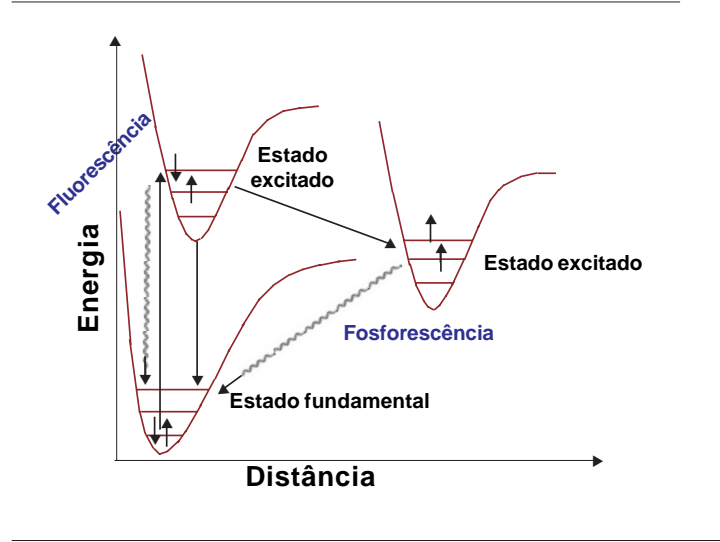

Fonte: Adaptado de Nery e Fernandez (2004); Atkins (2008).

O fenômeno de bioluminescência está relacionado com a emissão de luz por um organismo vivo, e pode ser observado nos vaga-lumes e em alguns gêneros de água-viva. Esse fenômeno é catalisado por uma enzima que oxida moléculas orgânicas presentes nesses organismos e, como consequência, ocorre a liberação de energia na forma de luz visível, h.v (VIVIANI; BECHARA, 2008). A quimiluminescência é a emissão de luz por meio de uma reação química, neste fenômeno, a energia necessária para a excitação dos elétrons do sistema provém de uma reação química. De acordo com Stevani e Baader (1999), ocorre a formação de uma substância no estado excitado que, pelo decaimento para o estado eletrônico fundamental, emite luz.

Esses diferentes tipos de emissão de luz estão fundamentados nas transições eletrônicas descritas nos postulados de Bohr. No caso das pulseiras luminosas, a emissão de energia na forma de luz ocorre por meio de reações químicas, por este motivo, é classificada como quimiluminescente.

As pulseiras luminosas são formadas por um tubo plástico que contém uma ampola de vidro em seu interior. Nesse tubo, encontram-se o peróxido de hidrogênio, o salicilato de sódio e o dibutil ftalato; na ampola de vidro, estão o corante e o éster de fenil oxalato. Para iniciar a reação nessas pulseiras, a ampola de vidro interna deve ser quebrada fazendo com que seus componentes se misturem.

Quando misturados, o peróxido de hidrogênio oxida o éster de fenil oxalato para formar fenol e um dímero de alta energia de dióxido de carbono, também conhecido como 1,2-dioxetanodiona. Esse dímero por ser altamente instável, decompõe-se em duas moléculas de dióxido de carbono, gerando grande quantidade de energia que é transferida ao corante. Devido à energia absorvida, os elétrons do corante são excitados a um nível mais externo, e 
ao retornarem ao seu estado fundamental liberam essa energia na forma de luz (KUNTZLEMAN; COMFORT; BALDWIN, 2009). As reações que ocorrem quando quebramos a pulseira luminosa estão representadas no Esquema 2.

Esquema 2. Etapas da reação que ocorre nas pulseiras luminosas

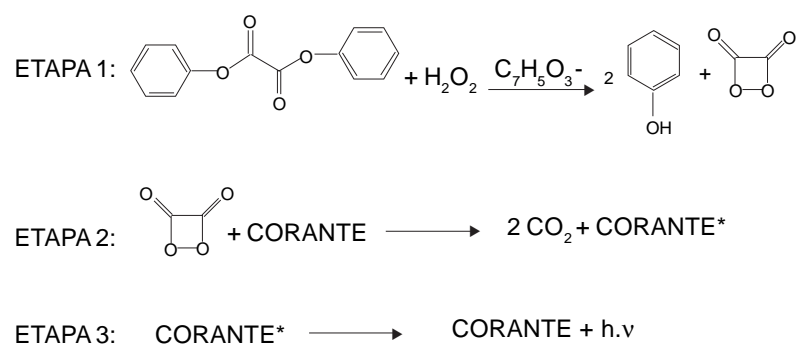

Fonte: Kuntzleman; Comfort; Baldwin (2009).

Os corantes são constituídos de moléculas naturais ou sintetizadas, cuja origem data de milhares de anos atrás (LE COUTEUR; BURRESON, 2006), e, atualmente, estão cada vez mais presentes em diversos materiais e no cotidiano. Diferentes corantes ou misturas de corantes são responsáveis pelas diversas cores das pulseiras luminosas, que podem variar do vermelho ao azul, compreendendo todas as cores do espectro eletromagnético. O Quadro 1apresenta a estrutura química e a nomenclatura de alguns corantes utilizados nessas pulseiras, relacionados com sua respectiva cor.

No processo de emissão de luz pelas pulseiras luminosas, elétrons da molécula do corante são promovidos para um estado excitado, e, ao retornarem, ao estado fundamental liberam a energia inicialmente absorvida pela clivagem do dímero 1,2-dioxetanodiona na forma de luz (Figura 2). Essas transições entre os níveis energéticos da molécula do corante estão relacionadas com os postulados descritos por Bohr, sendo uma das aplicações desta teoria.

Os compostos químicos presentes nas pulseiras luminosas podem ser isolados por meio de métodos físicos de separação, como, por exemplo, a cromatografia. Neste trabalho, durante a aplicação da oficina temática realizamos uma atividade experimental, que, por meio da construção de uma coluna cromatográfica com os estudantes, permitiu a separação dos componentes dessas pulseiras. Quando seus componentes são separados, a emissão de luz é cessada, entretanto, quando em contato novamente, a reação de quimiluminescência é reativada. Essa reação está baseada na emissão de luz resultante dos saltos eletrônicos; desta forma, essa atividade experimental pode ser uma alternativa para promover o entendimento do modelo atômico de Bohr. 
Quadro 1. Nomenclatura e estrutura química dos corantes encontrados nas pulseiras luminosas.

\begin{tabular}{|c|c|c|c|}
\hline Cor & Nomenclatura & $\begin{array}{c}\text { 1,5-dicloro-9,10- } \\
\text { bis(feniletinil)antraceno }\end{array}$ \\
Amarela & $\begin{array}{c}\text { 5,12- } \\
\text { bis(feniletinil)naftaceno }\end{array}$ \\
Púrpura & $\begin{array}{c}\text { 9,10-bis(4- } \\
\text { metoxifenil)-2-cloro- } \\
\text { antraceno }\end{array}$ \\
\hline
\end{tabular}

Fonte: Elaborado pelos autores.

Figura 2. Diagrama dos níveis energéticos da molécula do corante

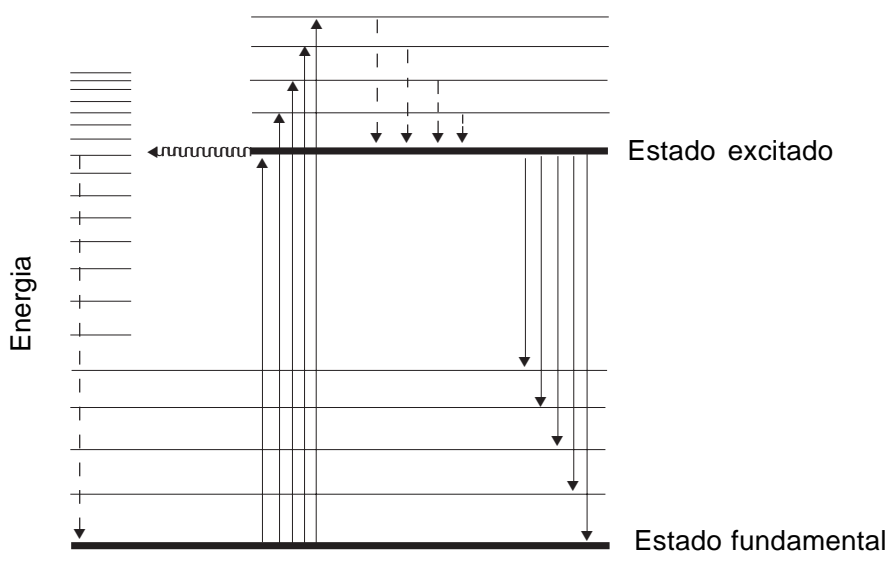

Fonte: Adaptado de Kuntzleman; Rohrer; Schultz (2012).

\section{Metodologia desenvolvida}

A oficina temática foi desenvolvida para 25 alunos da $1^{\mathrm{a}}$ série do Ensino Médio da Escola Estadual de Ensino Médio Cilon Rosa na cidade de Santa Maria, Rio Grande do Sul, 
Brasil. Essa oficina foi planejada de acordo com as orientações propostas por Marcondes et al. (2007) e estruturada nos momentos pedagógicos (DELIZOICOV; ANGOTTI, 1991).

\section{Primeiro momento pedagógico: problematização inicial}

$\mathrm{Na}$ primeira parte, foram feitas questões problematizadoras com o objetivo de introduzir o conteúdo de modelos atômicos e fazer um elo com situações reais. O ponto culminante desse momento é fazer com que o aluno sinta a necessidade da aquisição de conhecimentos que ainda não detém. As questões feitas aos estudantes nesse momento foram:

- Em sua opinião, onde a Química está presente na sua vida?

- A Química está presente em festas e comemorações? Exemplifique.

- Você sabe o que é uma lightstick?

- Como funcionam quimicamente as pulseiras distribuídas nas festas?

Por meio desse questionário, foi possível realizar um levantamento dos conhecimentos prévios dos alunos em relação à temática. Ainda nesse momento, foi entregue, aos estudantes, um roteiro, com alguns conceitos importantes que seriam abordados durante a oficina. $O$ tempo estimado para a realização desta etapa da oficina foi de vinte minutos.

\section{Segundo momento pedagógico: organização do conhecimento}

Neste momento da oficina, os alunos foram orientados sobre os conhecimentos necessários para a compreensão do tema em estudo e da problematização inicial. Os conteúdos de Química abordados nesta parte da oficina foram: um breve histórico sobre a evolução atômica, modelo atômico de Bohr, incandescência, fluorescência, fosforescência, quimiluminescência e método de separação da cromatografia em coluna.

Após o desenvolvimento dos conteúdos citados acima, os alunos puderam compreender melhor os questionamentos feitos na primeira etapa da oficina, bem como entender outros aspectos relacionados com esses conteúdos, como o princípio de funcionamento dos fogos de artifício. A realização do segundo momento teve duração estimada de quarenta minutos.

\section{Terceiro momento pedagógico: aplicação do conhecimento}

Neste momento, foi realizado um experimento demonstrativo, que teve por objetivo relacionar o modelo atômico de Bohr com o funcionamento das pulseiras luminosas, por meio da separação de seus componentes polares e apolares para cessar a emissão de luz. Após a separação dos componentes, os mesmos foram misturados novamente para que a emissão de luz fosse regenerada.

Primeiramente, para a separação dos componentes da pulseira luminosa, foi construída, juntamente com os alunos, uma coluna cromatográfica (Figura 3).

Os materiais e reagentes necessários para a realização da atividade experimental foram: uma bureta de $25 \mathrm{~mL}$, um funil, três béqueres de $250 \mathrm{~mL}, 15$ frascos pequenos (tipo penicilina), duas espátulas, um conta gotas, um estilete, um suporte universal, duas garras, algodão, pedaço de mangueira, arame, água, hexano, 8g de sílica gel 60 (230-400 mesh), 3g de 
Figura 3. Coluna cromatográfica.

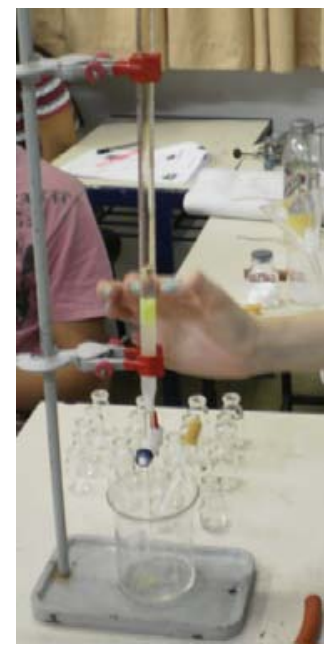

Fonte: elaborada pelos autores.

bicarbonato de sódio, $1 \mathrm{~mL}$ de peróxido de hidrogênio 3\%, $3 \mathrm{~g}$ de ácido salicílico e uma pulseira luminosa de cor amarela (para uma melhor visualização da emissão de luz foi escolhida a cor amarela).

Para a construção da coluna cromatográfica, colocou-se, com o auxílio de um arame, um pequeno pedaço de algodão dentro da bureta para impedir a passagem da sílica pela torneira. A bureta foi fixada no suporte universal com o auxílio das garras, e, em um béquer contendo $8 \mathrm{~g}$ de sílica gel 60 (230-400 mesh), foi adicionada uma quantidade suficiente de hexano para a obtenção de uma suspensão homogênea. Por meio da utilização de um funil, derramou-se a mistura sílica/hexano na bureta e, para empacotar a coluna, bateu-se levemente, com uma mangueira, na bureta.

A pulseira foi ativada (dobrando-a de forma a quebrar a ampola interna) e, com o auxílio de um estilete, uma das extremidades foi cortada para que seu conteúdo líquido fosse recolhido em um béquer. Com um conta-gotas, adicionou-se a mistura da pulseira à coluna empacotada (bureta). Na medida em que os componentes da pulseira luminosa foram percorrendo a coluna, diferentes frações foram recolhidas nos frascos de penicilina previamente numerados.

O princípio da separação dos componentes das pulseiras luminosas está baseado na diferença de polaridade de seus constituintes; à medida que são eluídos através da coluna, a intensidade da emissão de luz diminui gradativamente. As frações recolhidas não apresentaram emissão de luz, uma vez que houve a separação dos componentes da pulseira. Para provar que essa separação ocorreu e que a emissão de luz pode ser restabelecida, todas as frações obtidas foram adicionadas em um béquer contendo uma solução saturada de ácido salićlico, bicarbonato de sódio e peróxido de hidrogênio, pois esses compostos ficaram retidos na fase estacionária da coluna (devido ao caráter polar). Em seguida, os estudantes puderam observar, novamente, a emissão de luz resultante da transição eletrônica descrita nos postulados de Bohr, em um comprimento de onda com intensidade muito próxima da luz emitida pela pulseira apresentada anteriormente. 
Ainda neste momento, os alunos responderam a um segundo questionário, que teve por objetivo detectar os conhecimentos adquiridos após a realização da oficina. As questões feitas foram:

- Após participar desta oficina, você conseguiu relacionar a Química com as festas que você frequenta?

- Você conseguiu entender o modelo atômico de Bohr, após a realização do experimento?

- Como funciona uma pulseira luminosa?

- Quais outros temas você gostaria que fossem estudados nas aulas de Química?

O tempo utilizado para a realização do terceiro momento foi de, aproximadamente, quarenta minutos, portanto o tempo total estimado para a realização da oficina foi de cem minutos (correspondentes a dois períodos de aula na escola).

\section{Análise e discussão dos resultados}

Esta pesquisa apresenta características predominantemente qualitativas, pois foi desenvolvida no ambiente natural dos sujeitos da pesquisa e valoriza a subjetividade por meio da observação e do material obtido durante a realização da oficina (GÜNTHER, 2006). Para a análise dos dados, utilizamos a análise textual discursiva. De acordo com Moraes (2003):

Pesquisas qualitativas têm cada vez mais se utilizado de análises textuais. Seja partindo de textos já existentes, seja produzindo o material de análise a partir de entrevistas e observações, a pesquisa qualitativa pretende aprofundar a compreensão dos fenômenos que investiga a partir de uma análise rigorosa e criteriosa desse tipo de informação, isto é, não pretende testar hipóteses para comprová-las ou refutá-las ao final da pesquisa; a intenção é a compreensão. (p. 191)

A partir das informações obtidas, por intermédio da aplicação dos questionários, optamos em classificar os dados em três categorias:

1) Percepção da relação entre a Química e o cotidiano;

2) Evolução do pensamento químico;

3) Outras temáticas para aulas de Química.

\section{Percepção da relação entre a Química e o cotidiano}

A presença da Química no cotidiano das pessoas é mais do que suficiente para justificar a necessidade de o cidadão ser informado sobre essa Ciência (SANTOS; SCHNETZLER, 2003). O ensino de Química deve ser um agente facilitador no entendimento do mundo; para isso. os alunos devem ter condições de relacionar e interpretar o cotidiano por meio do conhecimento químico. Em relação à presença da Química em sua vida, selecionamos alguns relatos que contemplam as ideias dos sujeitos dessa pesquisa em sua totalidade. 
Aluno F: A Química está presente em quase tudo o que a gente imagina, nos alimentos, nos metais, na natureza e etc.

Aluno K: Está presente em tudo o que como, no que bebo e no ar que respiro.

Aluno L: Em alguns alimentos, no bujão de gás da cozinha e na eletricidade.

Aluno O: A Química está presente em tudo, desde os produtos que utilizamos para a bigiene pessoal até nos alimentos que ingerimos.

Analisando os relatos dos alunos selecionados, percebemos que todos relacionam a Química com o tema alimentos. Nas respostas dos alunos F e O, constatamos que os estudantes têm a noção de que a Química abrange vários fenômenos do nosso dia a dia, porém observamos que o aluno F percebe a Química em "quase" tudo, diferente do aluno O que afirma que a Química está presente em tudo. Outros temas como natureza, higiene pessoal, eletricidade e ar também foram mencionados pelos estudantes.

\section{Evolução do pensamento químico}

Para a análise da evolução do pensamento químico dos alunos nos baseamos nas respostas obtidas no primeiro momento e terceiro momento da oficina. No primeiro questionário, os estudantes foram perguntados a respeito do funcionamento químico das pulseiras distribuídas em festas. Algumas respostas foram:

\footnotetext{
Aluno A: Eu sei que elas [pulseiras] brilham.

Aluno C: Elas são quebradas e o líquido brilha.

Aluno D: Não sei, nunca parei para pensar como as pulseiras funcionam.

Aluno H: Não sei responder corretamente, mas eu acho que o que tem dentro das pulseirinhas é ácido.

Aluno M: Sinto que quando quebro a pulseira, há um tipo de vidro, acho que contém algo que reage e dá cor.
}

A maioria dos alunos apresentou alguns conhecimentos prévios em relação ao funcionamento químico das pulseiras, como, por exemplo: que, quando quebradas (ativadas), brilham; que ocorre uma reação, e a presença de ácido. Entretanto, o aluno D afirmou nunca ter pensado a respeito e, por isso, não sabia responder. Por meio da análise das respostas do primeiro questionário, detectamos que, nesse momento, nenhum estudante conseguiu relacionar o funcionamento da pulseira luminosa com as transições eletrônicas descritas pelo modelo atômico de Bohr e com reações de quimiluminescência. Esses conceitos são fundamentais para o entendimento do princípio do funcionamento dessas pulseiras.

No final da oficina, os alunos responderam ao questionário 2 , no qual a primeira pergunta estava relacionada com o funcionamento da pulseira As respostas de alguns alunos foram:

Aluno A: O que ocorre na pulseira é uma reação quimiluminescente, pois quando os componentes reagem à luz é liberada, pois envolve muita energia. 
Aluno C: O vidro interno da pulseira é quebrado, os líquidos se misturam produzindo luz, e também, é errado dizer que é de neon.

Aluno D: Quando quebrado o que há dentro das lightsticks é liberada uma substância que se mistura a outra, gerando assim, a luz e a cor.

Aluno H: Os elétrons dela [pulseira] obtém muita energia de uma reação e saltam para outro nivel. Quando voltam ao estado fundamental liberam a energia na forma de lu:

Aluno M: Na ampola de vidro há o corante, do lado de fora há componentes que ao quebrar a ampola acionam o mecanismo de quimiluminescência do corante, dando a luminosidade. Catalisadores acionam o corante.

Ao analisarmos as respostas, após o desenvolvimento da oficina temática, constatamos que os alunos conseguiram explicar o funcionamento das pulseiras luminosas utilizando conceitos científicos relacionados com as reações de quimiluminescência e com o modelo atômico de Bohr, como, por exemplo, níveis eletrônicos e transições eletrônicas.

$\mathrm{O}$ aluno A, antes de participar da oficina temática, quando perguntado sobre o funcionamento químico das pulseiras distribuídas em festas, afirmava que elas simplesmente brilhavam; após a oficina, conseguiu associar o princípio das pulseiras com a reação de quimiluminescência e liberação de energia na forma de luz. Durante a oficina temática, foi discutida, com os alunos, a maneira equivocada como as lightsticks ou pulseiras luminosas são conhecidas. Neste momento, explicamos que seu funcionamento não está relacionado com a presença do gás neônio, como sugere a denominação atribuída às pulseiras. Isso pode ser observado na resposta do aluno $\mathrm{C}$ no questionário 2.

As respostas dos alunos C e D, após a oficina, indicam que a observação de luz e cor é proveniente de uma mistura das substâncias presentes na pulseira quando quebradas. Embora esse pensamento seja pertinente, está incompleto, pois a observação de luz e cor está relacionada às reações que ocorrem quando os componentes da pulseira são misturados. Em seu relato, o aluno $\mathrm{H}$ explica o funcionamento das pulseiras luminosas por meio do modelo proposto por Bohr.

Antes de participar da oficina temática, o aluno $\mathrm{M}$ atribuiu a liberação de luz pelas pulseiras a uma reação química. Em sua resposta final, podemos observar um enriquecimento do vocabulário científico bem como a noção da utilização de catalisadores nas reações químicas.

\section{Outras temáticas para aulas de Química}

No término da oficina, os estudantes foram questionados sobre quais outros temas gostariam que fossem abordados nas aulas de Química; algumas respostas foram:

Aluno G: Me interessa aprender sobre a Química dos alimentos.

Aluno O: Tudo que explode, as bombas de fabricação caseira.

Aluno B: A Química do ar.

Aluno K: Os fogos de artifícios que são usados nas festas. 
Aluno E: Os temas que ensinam é de grande ajuda, não tenho interesse em outros.

Corroborando a resposta do aluno $\mathrm{G}$, grande parte da turma tem interesse em estudar a Química relacionada com a temática Alimentos. Alguns temas que também foram citados são: bombas e materiais explosivos, a Química do ar, e fogos de artifício. Entretanto, alguns estudantes, como, por exemplo, o aluno E, não têm interesse em nenhum outro tema.

\section{Considerações finais}

O desenvolvimento do conceito de átomo demanda que o processo de ensino e aprendizagem envolva noções abstratas, além da concepção de modelos, palavras e símbolos. O processo de apropriação desse conceito pode adquirir características muito complexas em vista do reconhecimento de que é um modelo científico e, como tal, transitório, uma hipótese que contribui para a interpretação da constituição e das propriedades das substâncias (ROMANELLI, 1996).

Partir de temas significativos proporciona uma maior participação dos alunos nas diferentes atividades desenvolvidas em sala de aula. Isso foi observado durante o desenvolvimento da oficina temática "A Química presente em sua festa", em que aspectos do cotidiano dos estudantes foram considerados, juntamente com seus conhecimentos prévios, para a construção do conhecimento químico. Além disso, constatamos que a utilização de atividades experimentais, como a que foi desenvolvida no terceiro momento da oficina, foi uma estratégia que auxiliou na visualização em escala macroscópica dos conceitos químicos relacionados ao modelo atômico de Bohr.

Para avaliar as contribuições dessa intervenção na aprendizagem dos estudantes foram aplicados questionários investigativos. A fim de facilitar a interpretação dos dados obtidos, foram identificadas três categorias: percepção da relação entre a Química e o cotidiano, evolução do pensamento químico, e outras temáticas para as aulas de Química.

A percepção da relação entre a Química e o cotidiano pelos alunos está em várias situações do dia a dia, como, por exemplo: nos alimentos, na higiene pessoal, na natureza, entre outros. A associação da Química com aspectos do cotidiano é importante no desenvolvimento de competências e habilidades que auxiliam no exercício da cidadania pelos estudantes. A evolução do pensamento químico foi evidenciada pelas respostas embasadas em conceitos, teorias e linguagem científica adquiridos pelos alunos durante a oficina. Ao formarem seu pensamento químico, por meio da intervenção do professor e da linguagem química, os alunos são capazes de interpretar e posicionar-se criticamente nas mais variadas situações. Em relação à terceira categoria, outras temáticas para as aulas de Química, os alunos mostraram interesse nos seguintes temas: alimentos, bombas e materiais explosivos, a Química do ar, e fogos de artifício.

Considerando as poucas propostas didáticas disponíveis na literatura e os conceitos abstratos necessários para a compreensão do modelo atômico de Bohr, é necessário que os professores utilizem estratégias de ensino que auxiliem na aprendizagem dos estudantes. Desta forma, acreditamos que esse trabalho é de extrema importância para a área de ensino de 
Ciências, pois apresentamos os conceitos relacionados ao modelo atômico de Bohr de uma maneira contextualizada e em escala macroscópica por meio do desenvolvimento de uma atividade experimental.

\section{Referências}

ABDALLA, M. C. Bohr: o arquiteto do átomo. São Paulo: Odysseus, 2006.

ATKINS, P. W.; JONES, L. Físico-Química. Vol. 1. 8. ed. Tradução Edilson Clemente da Silva et al. Rio de Janeiro: LTC, 2008.

CRANOR, E. U. S. Patent 6,267,914,2001: variable chemiluminescent process and product. Disponível em: <http://www.patents.com/us-6267914.html>. Acesso em: 13 abr. 2012.

DELIZOICOV, D.; ANGOTTTI, J. A. Metodologia do ensino de ciências. São Paulo: Cortez, 1991.

DELIZOICOV, D.; ANGOTTI, J. A.; PERNAMBUCO, M. M. Ensino de ciências: fundamentos e métodos. 3 ed. São Paulo: Cortez, 2009.

FARIAS, R. F. Para gostar de ler a história da química II. Campinas: Átomo, 2007.

FIGUEIREDO, W. G. Limitações da analogia entre sistemas planetários e modelos atômicos.

2008. 124 f. Dissertação (Mestrado em Educação Tecnológica) - Centro Federal de Educação

Tecnológica, Belo Horizonte, 2008.

GUNTHER, H. Pesquisa qualitativa versus quantitativa: esta é a questão? Psicologia: teoria e pesquisa, Brasília, v. 22, n. 2, p. 201-210, 2006.

HARRIS, T. How lightsticks work? Disponível em: < http://science.howstuffworks.com/ innovation/everyday-innovations/light-stick.htm>. Acesso em: 08 maio 2014.

KUNTZLEMAN, T. S.; COMFORT, A. E.; BALDWIN, E. B. W. Glowmatography. Journal of Chemical Education, Washington, v. 86, n. 1, p. 64-67, 2009.

KUNTZLEMAN, T. S.; ROHRER, K.; SCHULTZ, E. The chemistry of lightsticks: demonstrations to illustrate chemical processes. Journal of Chemical Education, Washington, v. 89, n. 7, p. 910-916, 2012.

LE COUTEUR, P.; BURRESON, J. Os botões de Napoleão: as 17 moléculas que mudaram a história. Rio de Janeiro: Jorge Zahar, 2006.

MAAR, J. H. História da química: primeira parte - dos primórdios a Lavoisier. Florianópolis: Conceito, 2008.

MALDANER, O. A.; SANTOS, L. P. Ensino de química em foco. Ijuí: Ed. Unijuí, 2010.

MARCONDES, M. E. R. Proposições metodológicas para o ensino de química: oficinas temáticas para a aprendizagem da ciência e o desenvolvimento da cidadania. Revista Em Extensão, Uberlândia, v. 7, p. 67-77, 2008.

MARCONDES, M. E. R. et al. Oficinas temáticas no ensino público: formação continuada de professores. São Paulo: Imprensa Oficial do Estado de São Paulo, 2007.

MORAES, R. Uma tempestade de luz: a compreensão possibilitada pela análise textual discursiva.

Ciência \& Educação, Bauru, v. 9, n. 2, p. 147-157, 2003. 
NERY, A. L. P.; FERNANDEZ, C. Fluorescência e estrutura atômica: experimentos simples para abordar o tema. Química Nova na Escola, São Paulo, v. 19, p. 39-42, 2004.

ROMANELLI, L.I. O professor e o conceito átomo. Química Nova na Escola, São Paulo, v. 3, p. 27-31, 1996.

ROSENAU, L. S.; FIALHO N. N. Didática e avaliação da aprendizagem em química. Curitiba: IBPEX, 2008.

SANTOS, W. L. P.; SCHNETZLER, R. P. Educação em química: compromisso com a cidadania. Ijuí: Ed. Unijuí, 2003.

SILVA, R. M. G. Contextualizando aprendizagens em química na formação escolar. Química Nova na Escola, São Paulo, v. 18, p. 26-30, 2003.

SILVA, R. R.; MACHADO, P. F. L. M.; TUNES, E. Experimentar sem medo de errar. In: SANTOS, W. L. P.; MALDANER, O. A. (Org.). Ensino de química em foco. Ijuí: Ed. Unijuí, 2010. p. 231-261.

STEVANI, C. V.; BAADER, W. J. O sistema quimiluminescente peróxi-oxalato. Química Nova, São Paulo, v. 22, n. 5, p. 715-723, 1999.

TRINDADE, L.S.P. A alquimia dos processos de ensino e de aprendizagem em química. São Paulo: Madras, 2010.

VIVIANI, V. R.; BECHARA, E. J. H. Um prêmio Nobel por uma proteína brilhante. Química Nova na Escola, São Paulo, n. 30, p. 24-26, 2008. 